unobjectionable. It may be several dioptries out of focus, in fact, and yet be exceedingly troublesome, especially if the image be small in size.

In regard to size of image, images III and IV will always be small by reason of the participation in their formation of reflection at the cornea with its comparatively small radius of curvature. These images are therefore more difficult to remove from the field of vision by turning the head or by similar expedients than are images I and II. On the other hand, a very slight variation in the distance between the lens and the cornea has an immense effect on their position, so much so that within the possibilities of practical adjustment of this distance it is very often possible to give a great measure of relief.

Even if it is not possible to select a type of lens which can be relied upon to give rise to no troublesome reflections, it is hoped that the data presented here will make it possible to determine what measure of relief, if any, can be given in any particular case.

Scientific Bureau

Bausch \& L L Optic Optal Co.

Rochester, N. Y.

August, 1917

\title{
THE EFFECT OF SIZE OF STIMULUS ON THE CONTRAST SENSIBILITY OF THE RETINA ${ }^{\mathrm{I}}$
}

\section{By Prentice Reeves}

When two visual stimuli are presented simultaneously or in immediate succession, we can judge them to be equal or unequal in brightness. The least difference in brightness that can be detected by the eye depends on several factors, viz., the brightness of the stimuli themselves, the time of adaptation of the eye to the contrasted stimuli, the previous adaptation of the eye and the size and shape of the visual fields. Numerous determinations of the least perceptible difference of brightness between two adjacent fields have been made, but in many cases the uncertainty in the statement of the brightness conditions and the time of adaptation have rendered the experiments of doubtful value. More precise measurements have been made when the stimuli follow one another in immediate succession, as seen in the numerous studies of flicker photometry, but even these are often discordant.

\footnotetext{
${ }^{1}$ Communication No. 70 from the Research Laboratory of the Eastman Kodak Company.
} 
In the Research Laboratory of the Eastman Kodak Company this least perceptible difference of brightness has been measured under definite conditions where the physical stimuli were accurately measured and carefully controlled by Dr. P. G. Nutting, Julian Blanchard and the writer. Blanchard investigated the contrast sensibility of the retina by means of a photometer bench and his data agree with those secured by König, ${ }^{2}$ providing König's brightness unit is taken as $0.004 \mathrm{ml}$ and sufficient time of adaptation is allowed, especially in the fainter intensities. Blanchard and the writer also studied the contrast sensibility by means of the visual sensitometer. ${ }^{3}$ Blanchard's results have been published in part by Nutting ${ }^{4}$ and will appear in full in a paper by Blanchard in the near future.

In the use of the visual sensitometer a $3 \mathrm{~cm}$ square test spot was used and a fixed contrast obtained by covering the upper half of the spot with a strip of neutral filter. This gave two adjacent fields of $3 \times 1.5 \mathrm{~cm}$ and with a fixed viewing distance of $35 \mathrm{~cm}$ the visual angle was 5 degrees by 2.5 degrees. By using a series of filters in the upper field, which transmitted from o to 97 per cent of the lower field intensity, five suitable fixed contrasts were obtained. In the experiment the observer remained in total darkness for fifteen minutes to counteract any previous treatment of the retina and to assure the same retinal condition for all observations. The eye was then adapted to the sensitizing field brightness, the field turned off, and by repeated efforts the test spot intensity was adjusted until the contrast could just be perceived the instant the sensitizing field was extinguished. This procedure was then repeated for I, 2, 5 on to 60 seconds adaptation after turning off the sensitizing brightness.

The writer first repeated Blanchard's experiment for all contrasts with an initial sensitizing brightness of $0.1 \mathrm{ml}$ and the test spot $3 \mathrm{~cm}$ square viewed from a distance of $35 \mathrm{~cm}$, with the natural pupil of the right eye, the left eye being closed. The results of the observers agree within the uncertainty in a single series of observations and the curves in Fig. I show the time and brightness to detect the five fixed contrasts. The writer's next step was to investigate the effect of reducing the size of the test spot to a I $\mathrm{cm}$ square, with the procedure otherwise remaining the same. The data in Table I give the results obtained for the two different stimuli for all contrasts and Fig. 2 shows the curves for three contrasts. The next step

2 A. König-Physiologische Optik. pp. 116, 135.

3 Described by Nutting-Trans. Ill. Eng. Soc., 1916, 11, 1-21.

4 P. G. Nutting-Trans. I1l. Eng. Soc., 1916, 11, 939-946, J. Franklin Inst. 1917, 183, 287-302. 


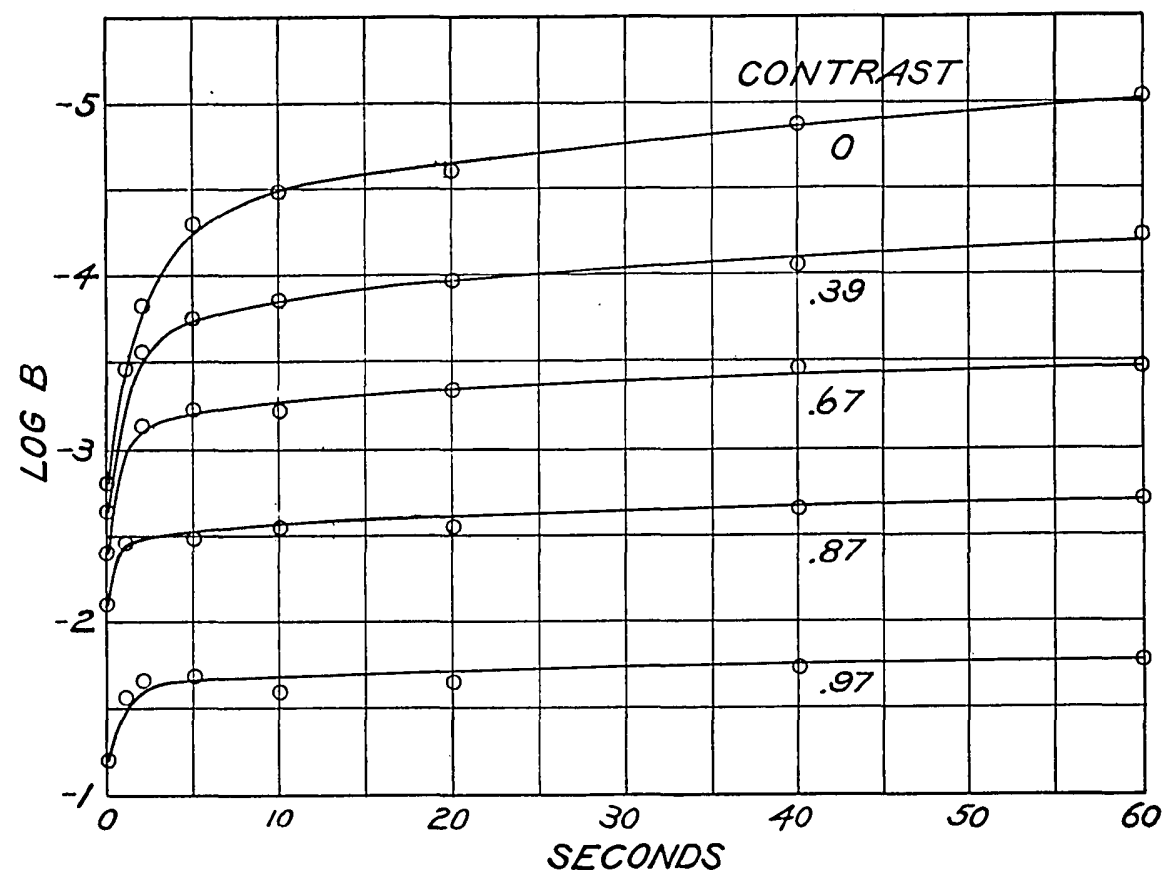

Fig. 1

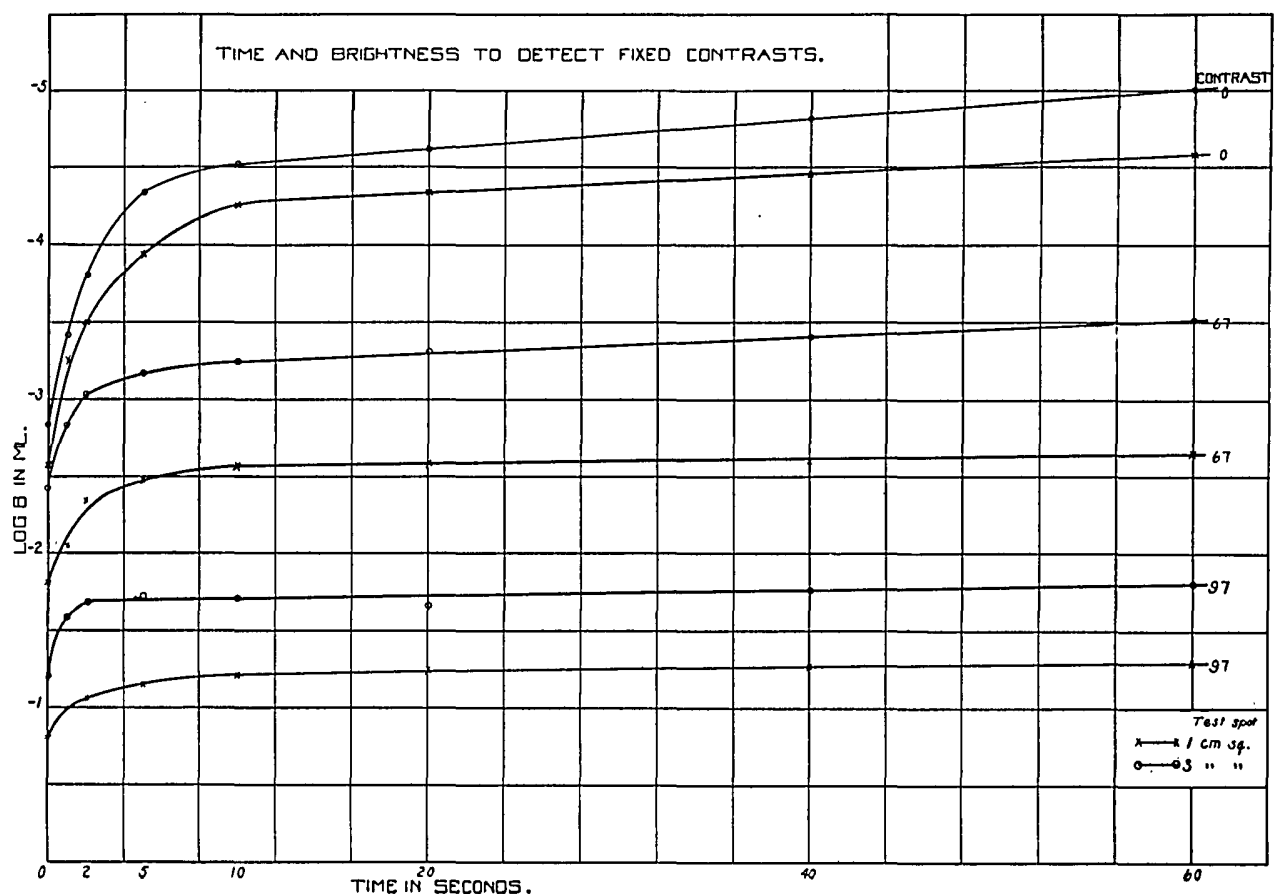

Fig. 2 


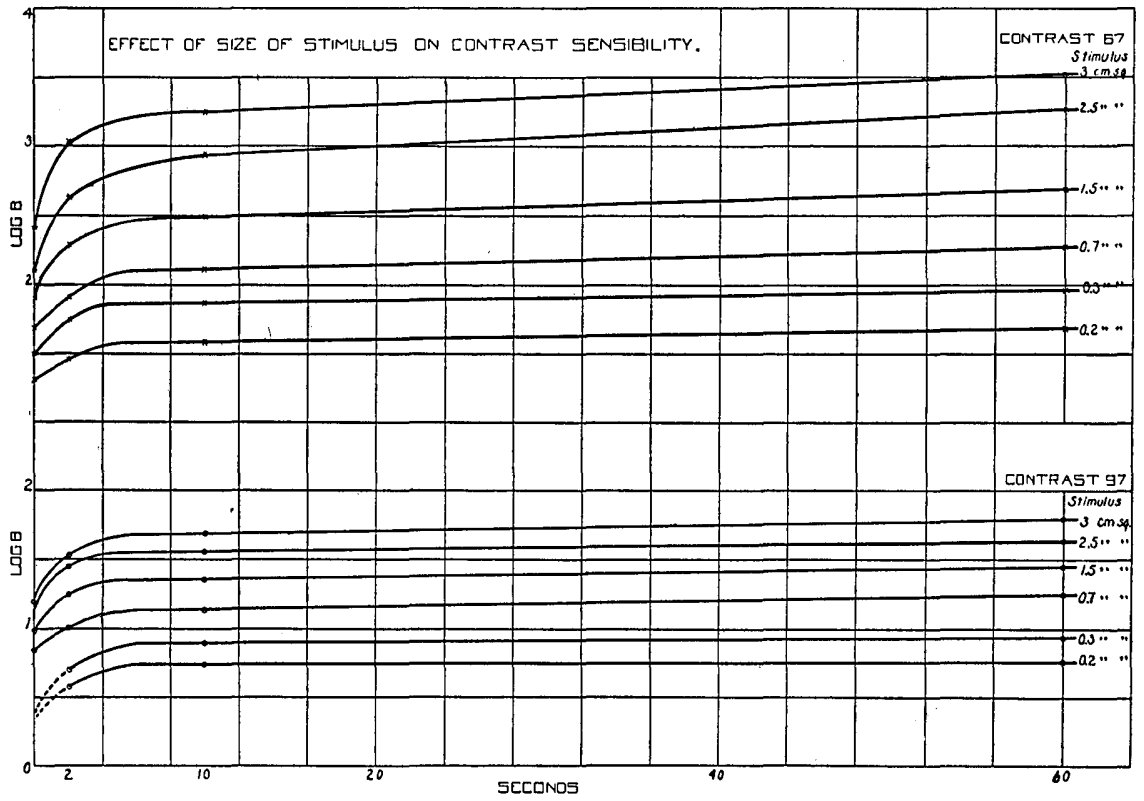

Fig. 3

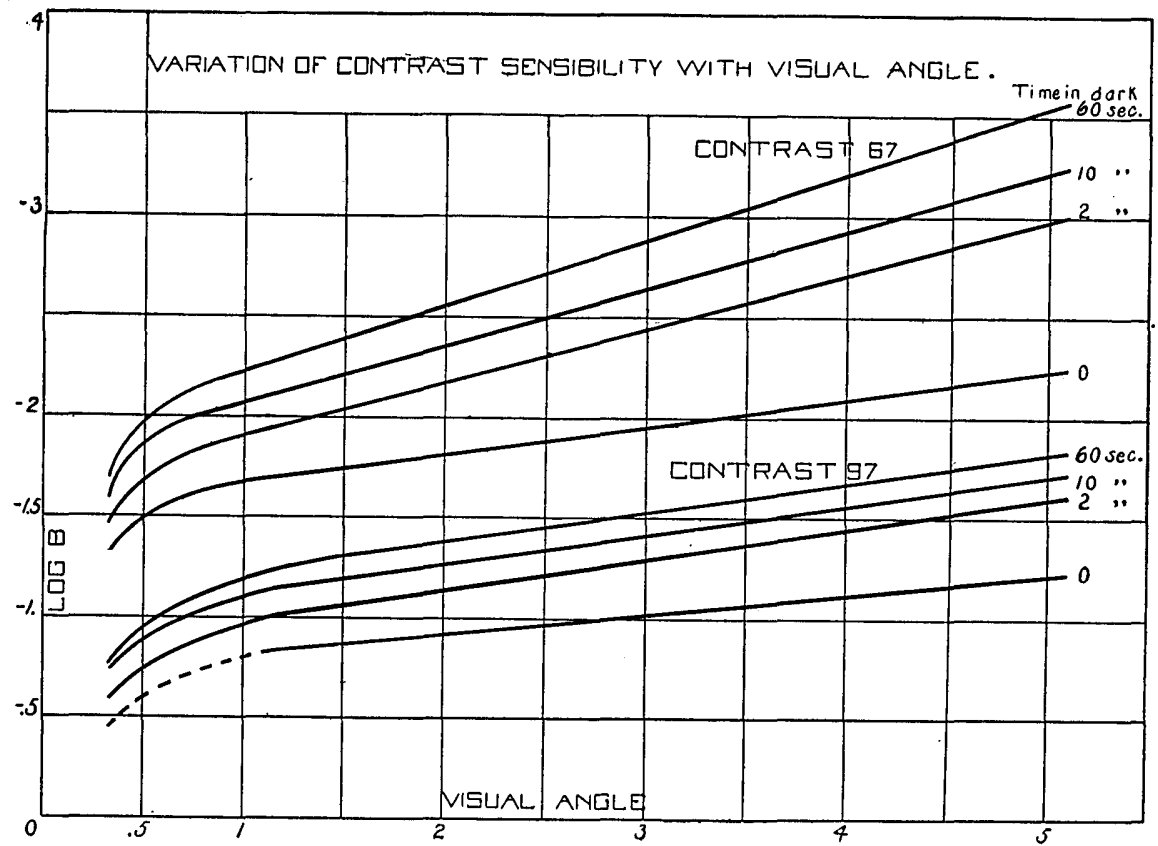

Fig. 4 
in the experiment was to obtain results for various sizes of the test spot from a $3 \mathrm{~cm}$ square to a $2 \mathrm{~mm}$ square and Table II and Fig. 3 show the results for fixed contrasts of 67 and 97 per cent.

Now if we take Table II, convert the size of stimuli into terms of visual angles and take the values of $\log I$ at points where time is equal to o, 2, Io and 60 seconds, we get the variation of contrast sensibility with the visual angle. These results are shown in Table III and represented graphically in

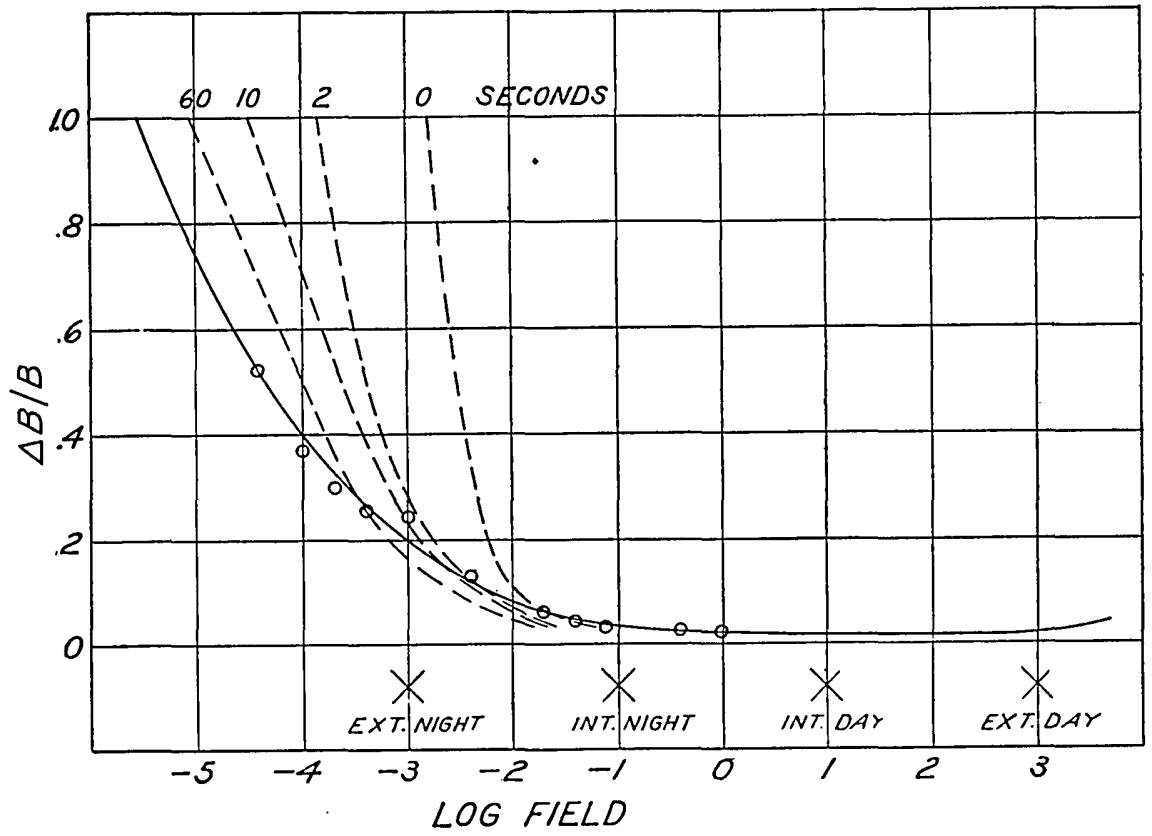

Fig. 5

Fig. 4. Another interesting method of presenting these data is to obtain the Fechner fraction, which is the ratio of the least perceptible difference in brightness to the brightness for which it was determined and this value $\triangle \mathrm{B} / \mathrm{B}$ plotted against $\log \mathrm{B}$ enables us to see at a glance the effect of time of adaptation and of the brightness on the contrast sensibility. Fig. 5 shows the curves plotted for the $3 \mathrm{~cm}$ square spot. If we plotted the data from the smaller test spots, the curves would remain the same relative shape, but would be shifted to the right. An inspection of all the curves 
will show that, in general, the effect of decreasing the size of the stimulus, hence the visual angle, is to raise the intensity of the illumination necessary to detect the contrast for a given time of adaptation, or to increase the adaptation time necessary with a fixed intensity. When both the contrast and visual angle are decreased, the above changes are greatly increased.

The possibilities of application of these results are quite extensive and it is desirable to secure further data of similar nature. Take for example the visual detection of air planes. If we assume a spread of 40 feet in the plane, the data obtained from the $3 \mathrm{~cm}$ test spot are applicable to a plane flying at a height of from 450 to 500 feet above the observer, while the $2 \mathrm{~mm}$ test spot data will apply to a plane 7000 feet above. If we know the average sky brightness under which the machine is to fly, we can approximate conditions under which the machine would be least visible for various heights. If we take the conditions under which the plane flying at 467 feet is just perceptible when the contrast between the plane and sky is 97 to Ioo, we find that for a height of 1400 feet a contrast of 87 is required for visibility, and if the plane flies at an elevation of 7000 feet the contrast required is 65 to Ioo. While the computation of the visual angle is not exact, precise determinations of the angle would only relatively effect the above statements.

\section{TABLE I}

Time and Brightness to Detect Fixed Contrasts

Eye Adapted to Initial Brightness of o. I ml Values, in Millilamberts, are Log Brightness of Brighter Field

\begin{tabular}{|c|c|c|c|c|c|c|c|c|c|c|c|c|}
\hline & & & \multicolumn{2}{|c|}{ Contrast o } & \multicolumn{2}{|c|}{ Contrast 0.39} & \multicolumn{2}{|c|}{ Contrast 0.67} & \multicolumn{2}{|c|}{ Contrast 0.87} & \multicolumn{2}{|c|}{ Contrast 0.97} \\
\hline & & & $\begin{array}{c}3 \mathrm{~cm} \\
\mathrm{sq} .\end{array}$ & $\begin{array}{c}\mathrm{r} \mathrm{cm} \\
\mathrm{sq}\end{array}$ & $3 \mathrm{~cm}$ & $\mathrm{I} \mathrm{cm}$ & $3 \mathrm{~cm}$ & $\mathrm{r} \mathrm{cm}$ & $3 \mathrm{~cm}$ & $\mathrm{I} \mathrm{cm}$ & $3 \mathrm{~cm}$ & I cm \\
\hline 0 & sec.. & & -2.83 & -2.57 & $-2.5^{8}$ & -2.17 & -2.42 & $-\mathrm{I} .80$ & $-\mathrm{I} .93$ & $-\mathbf{I} \cdot 36$ & $-\mathrm{I} .2 \mathrm{I}$ & -0.79 \\
\hline $\mathbf{I}$ & " & & $-3 \cdot 42$ & -3.26 & -3.10 & -2.49 & -2.84 & -2.04 & -2.17 & $-\mathrm{I} .5^{2}$ & $-\mathrm{I} \cdot 59$ & -0.99 \\
\hline 2 & $"$ & & -3.80 & -3.50 & -3.29 & -2.79 & -3.03 & -2.34 & -2.36 & $-\mathrm{r} .66$ & -1.68 & -1.07 \\
\hline 5 & “ & & -4.33 & -3.93 & -3.63 & -3.00 & -3.16 & -2.47 & -2.47 & $-\mathrm{r} .68$ & -1.72 & - I.I 5 \\
\hline IO & " & & $-4.5 \mathrm{I}$ & -4.27 & -3.75 & -3.07 & -3.25 & -2.57 & $-2.5 I$ & $-\mathrm{I} .76$ & $-x .70$ & $-\mathrm{I} .2 \mathrm{I}$ \\
\hline 20 & " & & -4.62 & -4.34 & -3.87 & -3.14 & $-3 \cdot 3^{2}$ & -2.59 & -2.56 & $-\mathrm{I} .78$ & $-\mathrm{x} .66$ & $-\mathrm{I} .25$ \\
\hline 40 & " & $\ldots \ldots$ & $-4.8 I$ & -4.44 & -4.05 & -3.27 & -3.40 & -2.59 & -2.59 & $-\mathrm{r} .8_{4}$ & -1.76 & -1.27 \\
\hline 60 & $" 6$ & $\ldots \ldots$ & $1-5.00$ & -4.59 & -4.20 & -3.44 & $-3.5^{2}$ & -2.64 & -2.68 & $-\mathrm{I} .82$ & $-\mathrm{I} .8 \mathrm{I}$ & $-\mathrm{I} .3 \mathrm{I}$ \\
\hline
\end{tabular}


TABLE II

Effect of Size of Test-Spot on Contrast Sensibility Contrast 0.67

\begin{tabular}{|c|c|c|c|c|c|c|}
\hline Adaptation & $3 \mathrm{~cm} \mathrm{sq}$. & $2.5 \mathrm{~cm}$ sq. & I. $5 \mathrm{~cm} \mathrm{sq.}$ & $0.7 \mathrm{~cm}$ sq. & $0.3 \mathrm{~cm}$ sq. & $0.2 \mathrm{~cm} \mathrm{sq} \cdot$ \\
\hline o sec.. & -2.42 & -2.10 & -1.90 & -1.69 & $-\mathrm{I} .49$ & $-I .3 I$ \\
\hline $2 "$ & -3.03 & -2.64 & -2.30 & $-I .9 I$ & -1.76 & -1.46 \\
\hline$" \ldots \ldots$ & -3.25 & -2.93 & -2.49 & $-2 . I I$ & -1.87 & - I. $5^{8}$ \\
\hline$" \ldots \ldots$ & $-3 \cdot 5^{2}$ & -3.25 & -2.69 & -2.27 & $-x .97$ & -1.69 \\
\hline
\end{tabular}

Contrast 0.97

\begin{tabular}{|c|c|c|c|c|c|c|}
\hline Adaptation & $3 \mathrm{~cm} \mathrm{sq}$. & $2.5 \mathrm{~cm}$ sq. & I. $5 \mathrm{~cm}$ sq. & $0.7 \mathrm{~cm} \mathrm{sq}$. & $0.3 \mathrm{~cm} \mathrm{sq}$. & $0.2 \mathrm{~cm} \mathrm{sq}$. \\
\hline o sec.. & $-\mathrm{I} .2 \mathrm{I}$ & -1.09 & -0.98 & -0.84 & & \\
\hline 26 & $-\mathrm{I} .54$ & $-\mathrm{I} .46$ & - I. 26 & $-\mathrm{I} . \mathrm{OI}$ & -0.70 & $-0.5^{8}$ \\
\hline Io " & -1.69 & $\rightarrow$ I. 56 & $-\mathrm{I} \cdot 35$ & 一I. I 4 & -0.88 & -0.74 \\
\hline $60 "$ " $\ldots$ & $-\mathrm{I} .80$ & $-\mathrm{I} .64$ & - I. 45 & -1.26 & -0.94 & -0.76 \\
\hline
\end{tabular}

TABLE III

Variation of Contrast Sensibility with Visual Angle Contrast 0.67

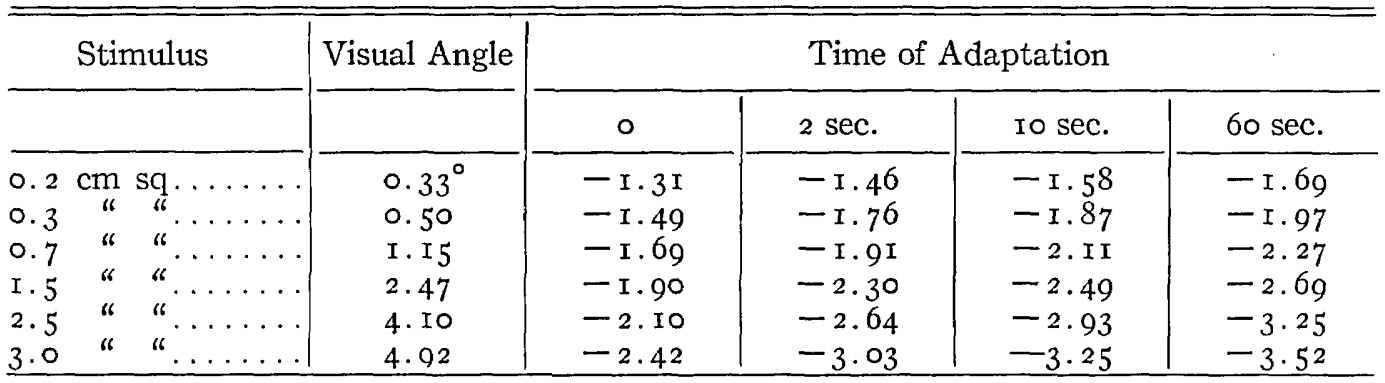

Contrast 0.97

\begin{tabular}{|c|c|c|c|c|c|c|}
\hline \multicolumn{2}{|c|}{ Stimulus } & \multirow{3}{*}{$\begin{array}{c}\text { Visual Angle } \\
\begin{array}{l}0.33 \\
0.50\end{array}\end{array}$} & \multicolumn{4}{|c|}{ Time of Adaptation } \\
\hline $0.2 \mathrm{c}$ & $\mathrm{cm} \mathrm{sq}$. & & $\ldots \ldots$ & $-0.5^{8}$ & -0.74 & -0.76 \\
\hline & " ". & & $\ldots \ldots$ & -0.70 & -0.88 & -0.94 \\
\hline 0.7 & " $"$. & I. I 5 & -0.84 & - I.OI & $-\mathrm{I} . \mathrm{I} 4$ & - I. 26 \\
\hline I. 5 & " $"$. & 2.47 & -0.98 & $-\mathrm{I} .26$ & $-I .35$ & $-\mathrm{I} .45$ \\
\hline 2.5 & " ". & 4. IO & $-\mathrm{I} .09$ & -1.46 & $-\mathrm{I} .56$ & $-\mathrm{I} .64$ \\
\hline 3.0 & " $"$ "... & 4.92 & $-I .2 I$ & $-\mathrm{I} .54$ & $-\mathbf{r . 6 9}$ & - I. 80 \\
\hline
\end{tabular}

Research Laboratory

EASTMAN KODAK COMPANY

Rochester, N. Y.

December 19,1917 